\title{
The Intelligent Society
}

\section{I5.I Background}

This book has shown that CI has been important throughout our history. This is not only a story about how we have been able to cooperate in increasingly larger groups, but also about how we have gradually improved our ways of solving problems together. It all began with intimate collaboration in dyads, and with time we gradually learned to solve problems with unknown others through human swarm problem solving. Our collective problem-solving abilities were further developed when we learned how to improve our tools, and it excelled when we learned how to store knowledge. The invention of writing enabled new types of knowledge sharing, and the printing press opened up the possibility of stigmergic problem solving at an unprecedented scale. The story of CI is not only about group size, but even more about our extraordinary ability to improve our ways of solving problems together.

With the invention of the Internet, $\mathrm{CI}$ is evolving into new and even more sophisticated forms. Because of mass communication, large-scale cooperation is now possible in previously unimagined ways. One of the most successful CI projects is Wikipedia, which illustrates how content production can be coordinated at a massive scale and with a diversity that is unimaginable without an online setting (Benkler, 2006; Castells, 2010). Originally, Pierre Lévy (1999) coined the term "collective intelligence" as a new, universally distributed "global brain" that is constantly evolving and in which all humans are part of the same environment for the first time in our history. The fundamental premise is that no one knows everything, everyone knows something, and all knowledge resides in humanity. The global brain assumes that solutions already exist; they only need to be rediscovered through search engines or other tools. Like all major social transformation, the basic feature relates to how our perception of space and 
time changes when geographical restrictions are removed and when the problem of information decay disappears.

In the mid-200os, we witnessed an enormous growth of previously private "vernacular creativity" becoming a part of the public culture through online social media, blogs, photo sharing, and videos. This new "participatory culture" (Jenkins, 2009) was associated with liberal and progressive ideologies about popular culture. Amateurs could actively participate in the creation and circulation of new content, and some foresaw the rise of a new culture centered on citizen engagement and democratic knowledge production. Technological change would lead to mass democratization, perhaps best illustrated by Time Magazine's announcement that the "Person of the Year" in 2006 was you. The techno optimism sought to revive a lost folk culture that could transform individuals and communities from passive consumers to co-producers and knowledge producers (Burgess \& Green, 2018). The goal in the Cape Town Open Education Declaration from 2008 is to create a world where "each and every person on earth can access and contribute to the sum of all human knowledge." It echoes Levy's vision of CI in its aim to make human knowledge accessible to anyone, independent of his or her economic income. Both open science and open democracy are children of the same ideas.

The main goal of the first part of this book was to describe mechanisms in three basic types of human collective problem solving that are all relevant for CI. What the analysis has shown is that many of these mechanisms are surprisingly similar with other animal groups. If we understand them better, we might also be better able to use them to solve our collective problems.

However, while technologies have made communication easy, there is no evidence that social media has improved our life quality. Although people have access to more knowledge than ever before, many seek misinformation or no information at all. More people are well educated, have more spare time and better writing skills, but they have still not become "hobby scientists" or "hobby politicians." With a few exceptions, the commercial tech companies dominate the Internet, and we are today witnessing the rise of alternative societal models that build on algorithms and machine intelligence. Zuboff (2019) claims that this new instrumentarian power or instrumentarian intelligence has already become the dominant societal power. This final chapter describes the basic characteristics of this intelligence. It will be shown how it differs from civic intelligence, a societal intelligence that builds on CI. 


\subsection{Instrumentarian Intelligence}

Instrumentarian intelligence is already here. Techno optimism is back, but it is no longer about Web 2.0, but big data. For the first time in human history, massive amounts of behavioral data are being collected in all areas of our life. By using the power of machine intelligence, the goal is to reveal the hidden truth of who we really are as humans. All large tech companies, with Google and Facebook at the forefront, are pursuing more of this human behavioral surplus because of the knowledge it can provide. Today, the companies are even colonizing the world of things through digital sensors, surveillance cameras, and facial recognition technologies. A richer set of data can provide an even better prediction of human behavior. The ultimate goal in this surveillance capitalism is to replace the mystery of the unknowable market mechanisms with certainty, mapping out the graph of everything. Human experience is today being reborn in the market as behavior: the fourth "fictional commodity that is different from land, labor, and money, still largely unregulated by law" (Zuboff, 2019).

A fundamental assumption is that humans are nothing more than a moving object surrounded by social fabric that can now be constantly monitored. Complex social phenomena can be analyzed as aggregations of billions of small behavioral transactions. For example, automatically aggregated Facebook ads build on data from a wide range of online activities, including what users explicitly share, favorite, and like. When users voice their opinion, the real value is the behavioral surplus it generates that makes the algorithms even more precise. The News Feed function in Facebook is a secret predictive algorithm, consisting of more than I 00,000 data elements of behavioral surplus that continuously estimate a " personal relevancy score" as it not only scans your and your friends' behavior, but what everyone else that you follow does (Zuboff, 2019).

In return, the individual is offered social connection, information, and convenience, and an illusion of support through a multitude of "smart recommendations." The smart options provide individuals with simplified overviews and intelligent choices in an increasingly complex and chaotic world. Algorithms tell you what products you might like or where you might want to travel or whom you might want to meet, based on what you and your social network prefers. So why waste a lot of time looking for something when algorithms can do the job instead? This is an irresistible opportunity to live in a world where everything is arranged for your convenience. We are already getting so used to the comforts of "smart recommendations" that we don't stop using them, even if we don't like the 
hidden surveillance. Although people don't like being tracked and would prefer more privacy protection, they continue to use Google and Facebook (Zuboff, 2019).

Another basic characteristic with instrumentarian intelligence is its lack of transparency. It does not and cannot explain how the behavioral surplus will be used because hidden data are much more accurate. Human behavioral data are most valuable when they are unobtrusive, being outside of human awareness (Zuboff, 2019).

According to Zuboff (2019), instrumentarian intelligence is the unthinkable realization of Skinner's vision of a perfect totalitarian society. In his book Beyond Freedom \& Dignity, (I97I), Skinner prescribed a future based on behavioral control and a society built upon behavioral modification across entire human populations. By abandoning the illusion of individual freedom, one could, with the help of behavioral techniques, design a society built on collective values aimed at the greater good.

The main difference today is that the largest driver of behavioral modification is peer behavior. The millions of online social networks and interactions are assumed to reveal the true patterns of causality, enabling us to "engineer" even better social systems. Autonomous choice has been transformed into reinforcement, and action into conditioned response. "Social network incentives" is the new version of "reinforcement." Instead of focusing on individual behavioral change, it is more powerful to focus on changing the connections between people (Zuboff, 2019).

It is the behavioral patterns in groups and networks that can predict behavior more precisely than ever before. This is the new human superorganism, a swarm controlled through algorithms. Social pressure is an efficient means of behavioral modification, and is the mechanism that can ensure that all parts work in harmony toward collective aims. It makes it possible to transform machine learning into a hive mind where each element operates in harmony with every other element. This is a networked system moving seamlessly toward unity, where everyone share the same understanding, aiming to achieve the same outcomes in the most efficient way (Zuboff, 2019).

The assumption is that one can objectively determine what is correct through a mathematical, predictive science. These data can provide insight into who we really are, as more and more behavioral actions are digitized. The continuous streams of data about human behavior are powerful predictors of future behavior. They can be used to develop superior incentive design that eliminates chaos, conflict, and abnormality in favor of predictability and automatic regularity. It bears the promise of replacing fallible 
politics with a superior instrumentarian governance. Democracy creates friction that threatens the rational efficiency of the community as a single, high-functioning "superorganism." Political action is highly inefficient compared with the scientific schedules of reinforcement that aim for the greater good (Zuboff, 2019).

This neobehavioristic Skinnerian society, which once received so much criticism, is now here. The interest has shifted from using automated machine processes to map individuals' behavior to using machine processes to shape behavior according to the interests of surveillance capitalists. To governments, surveillance capitalism offers omniscience, control, and certainty. Government becomes convenient because "objective" algorithms can make decisions. Behavioral modification is placed at the heart of this system, administered by a specialist class that can implement the greater good for all (Zuboff, 2019).

This type of intelligence is now moving into the political domain, with the Chinese government being the first country to implement a nationwide reputation system. The private sector and local authorities have already used reputation systems for some years, but the new system represents a major shift from a "reputation society" to the rise of a "reputation state."

The comprehensive and mandatory Social Credit System (SCS) is the first digital nationwide scoring system in the world, which rates the behavior of citizens, companies, and other entities. The reputation scores combine both government information and personal reputation scores that have already been developed by private businesses (e.g., Sesame credit). The aim is to utilize the enormous amount of digital personal data in a system that can "improve" citizens' behavior and "build sincerity" in economic, social, and political life (Dai, 20I8). In this reputation state, advanced digital technology and powerful algorithms are at the core of a new and superior governing model. Every Chinese citizen is to have a file compiling data from public and private sources. All citizens receive a "grade" that builds on many different behaviors, and this grade will automatically change as the individual improves or worsens their behaviors. When citizens become aware of the importance of having a good reputational score, the idea is that they will constantly seek to gain rewards or avoid punishments for "the greater good of the Chinese society." The pilot programs in many different cities in China have already shown that behavioral modification at a macro level is possible. However, instrumentarian intelligence is now taken to new extremes, as the whole nation is included in a huge social experiment, which aims to be the foundation of its future society (Zuboff, 2019). 
From a political perspective, SCS aims to tackle many of the country's governmental problems, such as fraud, corruption, and difficulties in enforcing court judgments (Dai, 20I8). In the Chinese society today, there is a lack of honesty and trust among the population, which is illustrated by numerous reports about food poisonings, chemical spills, financial fraud, and academic dishonesty. According to one survey, "moral decline" was regarded as the largest problem in China in 2017, mentioned by 47 percent of respondents. In comparison, only I 5 percent of respondents from other countries mentioned the same issue (Engelmann, Chen, Fischer, Kao, \& Grossklags, 2019).

Furthermore, SCS is expected to boost the domestic economy because it will give millions of Chinese citizens without a financial history access to credit in the domestic market. In China, 225 million citizens have no bank account. Citizens can also use SCS to apply for loans based on trustworthiness scores, without having to prove their financial creditworthiness (Engelmann et al., 2019). The long-term goal is to avoid societal instability and cope with the social distrust (Zuboff, 2019). In the private sector, these scoring systems have already boosted the circular economy by introducing new ways that people can trust people they don't know ("The rise of the second-hand market in China boosts the circular economy," 2020).

In line with instrumentarian intelligence, the reputation score and the rating system covers a diverse range of behaviors which are not fully disclosed, but we know it includes a mix of online and offline actions on where you go, what you buy, and who you know. Some of the behavioral indicators are timely payment of invoices, contractual commitment, legal standing, and the degree of money gambling. One must also be careful about criticizing the government (Nspirement-Staff, 2020).

Just recently, SCS has raised controversy because a college rejected a student with a good social credit score because his father was on the blacklist of the system. This incident revealed that the calculations are not only built on individual behavior, but on an evaluation of your social network. The Chinese people are now becoming more concerned that SCS will turn into a feudal system where you are bound by the actions of others (Nspirement-Staff, 2020). It shows the huge challenge of designing a onedimensional system that everyone accepts and perceive as fair.

Zuboff (2019) claims that the Chinese reputation system can best be understood as the culmination of instrumentarian intelligence, with an authoritarian taking control over both public and private data. The Chinese leaders have in effect defined what is "good" and "bad" behavior 
across a variety of financial and social activities, and ratings are automatically aggregated based on citizens' behavior. The ingenious strategy in instrumentarian intelligence is that it motivates the social network to improve and influence each other in establishing the correct norms of behavior. If you are a Chinese citizen and want to get a better score, you either have to avoid contact with "bad" friends or try to make your friends behave better according to government policy. Thus, learning "good" behavior can be accelerated when it is shaped by a stronger form of social pressure, creating herding effects that make everyone adhere to the system rules (Zuboff, 2019).

This is neobehaviorism implemented in a totalitarian state. The state takes the role of being an authoritarian teacher, with the communist ideology as the curriculum. The algorithms are designed to achieve guaranteed social outcomes by providing different rewards and punishments through a schedule of reinforcements. "Good" behavior can result in material rewards and reputational gain, while "bad" behavior can lead to loss of material resources and reputation. The algorithms are described as the "fair eye" that constantly looks after its citizens (Zuboff, 2019).

Furthermore, the Chinese government has begun issuing behavioral information about the system on several platforms like the official SCS national website "Credit China" and its equivalent municipal outlet "Credit China (Beijing)." In one study, researchers examined 200,000 behavioral records and I, ooo reports on citizens' behaviors on these official sites. To some degree, the SCS is dependent on the citizens being able to distinguish between behaviors that result in reward and those that lead to sanction. Still, there is very little specific explanation of what characterizes "good" redlisted behavior. In general, the positive case stories on the website illustrate activities that intend to be "genuinely" moral, with no descriptions of material rewards. Instead, citizens gain reputation by being awarded symbolic honorary titles such as fulfilling legal obligations (Class A Taxpayer), performing professional (Taxi Star) or volunteering (FiveStar Volunteer) duties.

However, there is no explanation of the criteria that determine how an individual or a company can be awarded a symbolic title. The concealment of this information is in keeping with core principles in instrumentarian intelligence. If this information is published openly, positive norms may be turned into market transactions and weaken the intrinsic motivation. For instance, if one gets a higher score for being honest, individuals may do this to get a reward and not because it is good moral behavior. As with all 
behavioristic engineering designs, they can easily end up turning everyone into extrinsically motivated citizens. If there is very specific information on how to get on the redlist, people will become more focused on getting the prizes, which is a problem when there also are a limited number of prizes available (e.g., a first-class train ticket) (Engelmann et al., 2019).

In general, there is more information about the "bad" blacklisted behavior compared with the "good" redlisted behavior on the website. Blacklisted behaviors often refer to failure to pay back debt or informational misconduct (Engelmann et al., 2019). This list is not a new part of the system. The government has already reported thousands of defaulters that have missed executive positions at enterprises because of their debts or defiance of a court order. People on the list can be prevented from buying airplane tickets, bullet train, or first- or business-class rail tickets; selling, buying, or building a house; or enrolling their children in expensive feepaying schools. There are also restrictions on receiving honors and titles. If the defaulter is a company, it may not be able to issue shares, accept foreign investment, or work on government projects (Zuboff, 2019). In addition, Blacklists are used for public shaming in an attempt to motivate people to avoid ending up on the list (Engelmann et al., 2019). Public authorities even display photos and names of debtors in cinemas before people begin watching a movie (Zhang, 2020).

However, there is no specific information about the scoring mechanism behind blacklisted behavior (Engelmann et al., 2019). One new development with SCS is that it appears that just having a low score without being on the blacklist may have negative consequences. It can be more difficult to get bank loans, and your internet speed can be reduced. People also bring their personal ratings into every corner of their social life, as dating sites now allow users to publish their individual reputation score. People with lower scores risk being rejected by suitors (Nspirement-Staff, 2020). When the reputation score becomes part of social life, it becomes a part of one's identity. This amplifies the importance of the scoring system, as it merges online and offline behaviors into one single score for a human life.

The social comparison in the ranking system make people "measurable" and "quantifiable" in a way we have never seen before. When all people are positioned along a one-dimensional scalar measure, it makes it easy to assess who are more or less valuable than others. The simplicity of the score also makes it convenient and highly attractive to use. The fact that individuals have voluntarily started showing their score in dating apps illustrate how such systems rapidly become "normalized" and invade new social domains independent of the government original intentions. 
The rating system may create new social hierarchies. If the government rewards some individuals and penalizes others, it is likely that individuals will begin to do the same in social relationships, according to their reputation score. Individuals can easily compare themselves with others and assess their current performance in the system. While governments can exert a powerful control over people through surveillance technology, it is even more powerful when individuals begin to voluntary self-monitor and control their behavior accordingly.

From one perspective, this is a gamification of life itself; individuals will constantly be searching for new opportunities to acquire points and move towards the top of the leaderboard. However, instrumentarian intelligence cannot fully disclose its reward mechanisms. One study of the Sesame credit system in China indicates that the lack of understanding of what factors influence credit scores is likely to become a stressful experience for many individuals (McDonald \& Dan, 2020). Those who have a low score may discover that the credit system is designed to thrust their scores into an unavoidable downward spiral. When your score drops, you tell your friends, who, fearful of being negatively influenced by your score, quietly drop you as a contact. The algorithm notices that you have lost some of your "high-achiever" friends, and your score continues downwards (Zuboff, 2019).

Furthermore, the story about the rejected Chinese student raises the question to what degree our own history should follow us or haunt us. Although digital traces of most of our daily lives are stored, does this imply that all these data should be used? The SCS makes it more difficult to leave our personal histories behind. We would likely become overly cautious, with a constant worry about doing things wrong that cannot be forgotten. Since the logic behind the ranking is a secret, citizens are left to guess how they can improve their scores, by taking actions such as getting rid of friends with low scores, or try to find high-scoring individuals who can boost one's own rank (Zuboff, 2019).

Will people protest? One must remember that China is not a democracy, and has a long history of citizen surveillance. The "dang'an" is a wideranging personal dossier which includes hundreds of millions of Chinese citizens. It records the most intimate details of life, and is updated by teachers, Communist Party officials, and employers. Citizens have no rights to see its contents, and it has been used to surveil people for a long time (Zuboff, 2019). Nor is there a clear distinction between a private and a public sphere in Chinese society. The public interest is very important in Chinese civil law, with private information only being protected from 
disclosure when it refers to information that is irrelevant to the public interest (Engelmann et al., 2019).

The Chinese instrumentarian intelligence envisions a grandiose reputation state built on communist ideology, with the algorithms in the SCS being the core engine that constantly produces and updates "character" scores. This is a brave new world where the correct outcomes are known in advance and can be guaranteed through behavioral modification. Still, it remains to be seen if the Chinese people will let the machine hive become the model in which all citizens march in the same direction based on the same understanding of what matters most (Zuboff, 2019).

\section{I5.3 Civic Intelligence}

Early in the fifteenth century, a small and exclusive elite owned books. This situation changed dramatically with the invention of the printing press. Later in the same century, new print shops were popping up all over Europe at an unprecedented scale. These print shops became a meeting place for a diverse group of skilled workers. Each area of expertise required specific skill sets not shared with other professions. New occupational groups were required to do this new type of collective work, such as scholars, editors, translators, correctors, type designers, etchers, print dealers, engineers, carvers, and artists. Professional groups that previously had worked on books separately from each other, like illuminators, goldsmiths, university professors, clerks, monks, and preachers, were now brought together. Close contact between astronomers and engravers, physicians and painters, encouraged new ways of coordinating the work of brain, eyes, and hands. In those places where the workshop prospered, it became the most important cultural center, attracting local literati and celebrated foreigners; providing both a cross-cultural meeting place and "international house" for the expanding cosmopolitan book learning. The demand for vernacular scriptures and service books brought "communities of strangers" together, such as various religious groups on foreign soil who began to communicate with printers. Wealthy people also helped support this collective knowledge development and financed the expensive large Latin volumes that were used by late medieval faculties of theology, law, and merchants. As Eisenstein writes: "The print shop bridged many worlds and gave promise of a new and brighter future" (Eisenstein, I980: 55-56, 446-448) (Figure I 5.I).

A few decades into the internet revolution, we now have at our hands an even more powerful tool for cosmopolitan digital learning, but we are still 


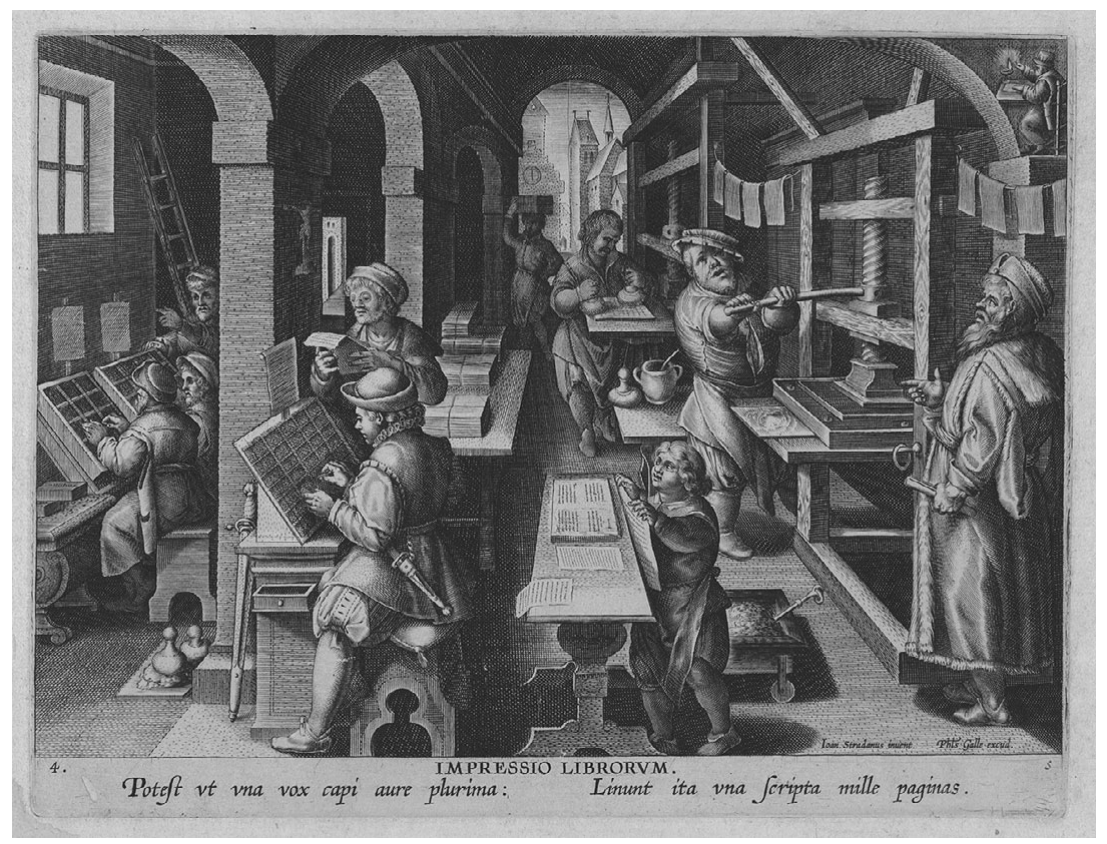

Figure I 5.I Printer's workshop in Antwerp, sixteenth century. Fourth plate from a print series entitled Nova Reperta (New Inventions of Modern Times) consisting of a title page and I9 plates, engraved by Jan Collaert I (ca. I 530-I 58I), after Jan van der Straet, called Stradanus, and published by Philips Galle around I60o. Illustration of men working at the book mill in Antwerp, Belgium. In the background, a man prepares paper for printing in the press depicted on the right. In a screw press such as that shown, each sheet had to be laid on the type, moved into the press, and pressure applied using the screw.

In the center of the foreground, a young boy lays out the newly printed paper for proofreading. On the left, workers set type to be printed. Credit Harris Brisbane Dick Fund, 1934. The Metropolitan Museum of Art, CCo r.o Universal Public Domain Dedication

far from having created anything that resembles these magnificent local "international houses" in our new global online setting. However, the stories from the virtual teams in online innovation contests describe meeting places that illustrate the seeds of a prosperous culture of creativity that brings strangers together. Wikipedia also stands out as a exemplary example of what is possible, in the increasingly polluted, commercialized, and corrupt ocean of information most people are struggling to cope with. There are interesting new experiments with participatory democracy, but the general trend is that democracies are struggling, and the Internet has not helped the case. Pointing to machine intelligence as the savior is 
tempting, but there is an increasing concern that both a "smart society" or a reputation state represent ideals far removed from the kind of society we really want.

In describing the collective knowledge advancement that emerged after the invention of the printing press, Lewis Mumford (1970) praised medieval "polytechnics" because it absorbed many important changes without losing the inventions and skills derived from earlier cultures. In the sixteenth century, polytechnics was still developing, as the exploration of the world brought both natural resources and technical processes back to Europe. For the first time in history, the art and polytechnics of the world began to learn from each other, to increase their practical effectiveness and symbolic expression. The power in polytechnics is that skills, esthetic judgements, and symbolic understandings are diffused throughout the whole community; they are not restricted to one specific group or occupation. Nor can they be reduced to a single, standardized uniform system, under centralized control (Mumford, I970: I40-I43).

In stark contrast, Mumford identifies "monotechnics", a new and powerful technological system that emerged at the same time. Inspired by political and military domination, monotechnics was built around mechanization and automation, with the goal of reaching out as far as possible; make everything faster and more efficient. Pride was to become associated with the many new technological achievements in mechanization and machine-made products, seen as major progress compared with the primitive agricultural and handcraft cultures of the past (Mumford, I970: I42-I43, I 55).

However, it is often not recognized that during the long transitional period from handicraft to complete mechanization, the crafts also multiplied and became more differentiated, contributing to societal innovation processes. For instance, there was a huge diversity of different types of small-scale mechanization in power-driven mills. While there were approximately 90 crafts in 1568 , this number had even increased to 250 crafts two centuries later. Nevertheless, by the end of the nineteenth century, most of the crafts had disappeared (Mumford, I970: I42-I43).

It was monotechnics, based upon scientific intelligence and quantitative production, that replaced polytechnics with its emphasis on economic expansion, material repletion, and military superiority. The change from traditional polytechnics into a uniform, all-embracing monotechnics also marked a shift from a limited goods economy, based on a diversity of natural functions and vital human needs, to a power economy, concentrated around the use of money. Human autonomy and diversity was 
sacrificed for a system of centralized control built around automation, speed, quantity, and control (Mumford, I970: 1 53-1 57, I65).

Is history repeating itself? Surveillance capitalism and instrumentarian intelligence can be regarded as the monotechnics of our time. Big data is available at an unprecedented scale, and we humans are using it at the utmost of our capabilities. The gigantic revenues and the powerful capabilities are far too tempting to resist.

On one hand, both the Internet and the digitization of information have led to human collective problem solving evolving into various new and more complex forms. Both the current pandemic and climate change show that it is vital that we learn how to organize our societies in ways that enable us to cope with the challenges of our time. On the other hand, because societies have become so complex, decisions need to be increasingly made by algorithms. As instrumentarian intelligence aims to become the dominant force, it is even more urgent to identify the areas where human collective problem solving should still be at the forefront. In the fight for what an intelligent society should be, the notion of civic intelligence (Schuler, De Liddo, Smith, \& De Cindio, 2018) can perhaps encompass many of the promising examples of $\mathrm{CI}$ in this book.

John Dewey once claimed that a democracy was not just about institutions and elections - the citizens also had to embrace diversity and discussion by adopting a scientific attitude with respect to the practical affairs in civil society. If the people themselves become dogmatic, and regard diversity as a threat, insisting that social arrangements should follow tradition, there will be no development, only conformity. Within his perspective, civic intelligence required people to speak freely, be allowed to criticize the system, and be open to listening to others (Anderson, 2006). In polytechnics, it is the needs, aptitudes, and interests of living organisms that are important (Mumford, I970: I 55 ).

In comparison with instrumentarian intelligence, civic intelligence highlights a use of technology controlled by the community and its citizens. In this sense, the "civic dimension" in CI is a critical alternative to the dehumanizing aspects of instrumentarian intelligence, which objectifies humans and reduces them to behavioral surplus. Building on the analysis in the book, I provide a tentative overview of how civic intelligence is different from instrumentarian intelligence (Table I 5.I).

The notion of civic intelligence is centered on values like responsibility, diversity, transparency, autonomy, and empowerment. As the different examples in this book has shown, the core value in civic intelligence is diversity, including informational, multicultural, cognitive, biological, and 


\section{Table I 5.I. A comparison of civic intelligence and instrumentarian intelligence. Two competing models for an intelligent society}

\begin{tabular}{|c|c|c|}
\hline & Civic intelligence & Instrumentarian intelligence \\
\hline \multirow[t]{3}{*}{ Technology } & $\begin{array}{l}\text { - Local technology and community } \\
\text { solutions are best. Participatory } \\
\text { design. }\end{array}$ & $\begin{array}{l}\text { - Universal, standardized } \\
\text { solutions are best. One size } \\
\text { fits all ("Megamachine"). }\end{array}$ \\
\hline & $\begin{array}{l}\text { - Open algorithms (e.g., open access, } \\
\text { open source). }\end{array}$ & - Hidden algorithms. \\
\hline & - Decentralized control. & - Centralized control. \\
\hline Learning & - Deliberation. & $\begin{array}{l}\text { - Social learning through } \\
\text { herding and social pressure. }\end{array}$ \\
\hline & - Peer learning. & $\begin{array}{l}\text { - Surveillance leads to stronger } \\
\text { self-monitoring of individual } \\
\text { behavior. }\end{array}$ \\
\hline \multirow[t]{4}{*}{$\begin{array}{l}\text { Governing } \\
\text { model }\end{array}$} & - Many citizens govern. & $\begin{array}{l}\text { - A few persons govern who } \\
\text { know what the best values } \\
\text { are (ideology-driven). }\end{array}$ \\
\hline & $\begin{array}{l}\text { - Process: Mass deliberation or mass } \\
\text { voting. }\end{array}$ & $\begin{array}{l}\text { - Process: Maximizing } \\
\text { collection of personal } \\
\text { information in both online } \\
\text { and offline settings. }\end{array}$ \\
\hline & $\begin{array}{l}\text { - The best society is developed } \\
\text { through inclusive deliberation } \\
\text { (Example: Ostbelgien and Ireland). }\end{array}$ & $\begin{array}{l}\text { - The best society requires a } \\
\text { reputation state (e.g., } \\
\text { China). }\end{array}$ \\
\hline & $\begin{array}{l}\text { - Slow implementation. The process } \\
\text { is part of the goal. }\end{array}$ & $\begin{array}{l}\text { - Time-efficient } \\
\text { implementation. Achieve } \\
\text { goal as quickly and accurate } \\
\text { as possible. }\end{array}$ \\
\hline $\begin{array}{l}\text { Who owns the } \\
\text { knowledge? }\end{array}$ & $\begin{array}{l}\text { - The people (e.g., knowledge } \\
\text { commons, open access). }\end{array}$ & $\begin{array}{l}\text { The state or big commercial } \\
\text { tech companies. }\end{array}$ \\
\hline $\begin{array}{l}\text { Theoretical } \\
\text { perspective } \\
\text { on humans }\end{array}$ & $\begin{array}{l}\text { - Unique individuals. } \\
\text { - Theories of diversity. } \\
\text { - Humanism. }\end{array}$ & $\begin{array}{l}\text { - Calculable individuals. } \\
\text { - Behaviorism. } \\
\text { - Totalitarianism. }\end{array}$ \\
\hline $\begin{array}{l}\text { CI vs. } \\
\text { machine } \\
\text { intelligence }\end{array}$ & $\begin{array}{l}\text { - Human-to-human intelligence } \\
\text { supported by machine intelligence. }\end{array}$ & $\begin{array}{l}\text { - Machine intelligence } \\
\text { (algorithms) supported by } \\
\text { human-to-human } \\
\text { intelligence. }\end{array}$ \\
\hline
\end{tabular}


Table I 5.I. (cont.)

\begin{tabular}{|c|c|c|}
\hline & Civic intelligence & Instrumentarian intelligence \\
\hline Transparency & - High. & $\begin{array}{l}\text { - Low (algorithms must be } \\
\text { hidden to be most effective). }\end{array}$ \\
\hline \multirow[t]{2}{*}{ Evaluation } & $\begin{array}{l}\text { - Continuous metadiscourses at all } \\
\text { levels in society. }\end{array}$ & $\begin{array}{l}\text { - Continuous statistical } \\
\text { feedback built on automated } \\
\text { algorithms. }\end{array}$ \\
\hline & $\begin{array}{l}\text { - Critical discourse (independent } \\
\text { journalism). }\end{array}$ & $\begin{array}{l}\text { - Critical discourse is } \\
\text { minimized because it } \\
\text { disturbs algorithmic accuracy } \\
\text { (state-controlled journalism, } \\
\text { censorship). }\end{array}$ \\
\hline \multirow[t]{2}{*}{ Individuality } & - Autonomy (freedom to choose). & - Constrained autonomy. \\
\hline & - Empowerment. & $\begin{array}{l}\text { - Smart recommendations that } \\
\text { restrict choices to a few } \\
\text { options defined by the } \\
\text { system. }\end{array}$ \\
\hline \multirow[t]{4}{*}{ Values } & $\begin{array}{l}\text { - Values develop through shared } \\
\text { understanding. }\end{array}$ & $\begin{array}{l}\text { - Important values can be } \\
\text { predefined. }\end{array}$ \\
\hline & - Responsibility, solidarity. & - Safety and trust. \\
\hline & $\begin{array}{l}\text { - Diversity (cultural, cognitive, } \\
\text { informational). }\end{array}$ & $\begin{array}{l}\text { - Conformism and rule } \\
\text { compliance. Diversity } \\
\text { threatens societal stability. }\end{array}$ \\
\hline & - Deviations and errors are valuable. & $\begin{array}{l}\text { - Errors threaten perfection } \\
\text { and should be eliminated or } \\
\text { avoided. }\end{array}$ \\
\hline Motivation & $\begin{array}{l}\text { - Cooperation and community } \\
\text { participation (intrinsic motivation). }\end{array}$ & $\begin{array}{l}\text { - Competition and } \\
\text { improvement of personal } \\
\text { reputation score (extrinsic } \\
\text { motivation). }\end{array}$ \\
\hline
\end{tabular}

participatory. Anything that threatens this diversity, like conformism or herding, will weaken the potential of $\mathrm{CI}$ in a society. What is perhaps a paradox, is that both civic intelligence and instrumentarian intelligence seek informational diversity, but in radically different ways. Instrumentarian intelligence hides its presence to produce the best predictions, while $\mathrm{CI}$ attempts to maximize transparency in areas such as open science and open democracy. 
The fight for civic intelligence will also be about the control of our collective memory. An enormous number of human knowledge products are being published openly today. People publish text, images, and videos, which others can locate at any point in time. Between these huge numbers of both content producers and consumers, there are relatively few search engines and social media platforms, which operate as the switchboards to decide what content should be given attention (Halavais, 201 8: I 20). For example, the debates around the value and legitimacy of YouTube have raised questions regarding who gets to speak, who gets the attention; what compensations or rewards are given for the work; and how trustworthy are the various forms of expertise and authority (Burgess \& Green, 2018: I9). Today, only a few winners receive the majority of the attention on the Internet, and social groups that are already powerful tend to amplify their position.

It has even been suggested that modern military conflict will become knowledge-centric: "about who knows, what, when, where, and why." Search engines are vital in this informational war, and those interested in telling what is true will be interested in shaping such systems (Halavais, 2018: 239). In the age of television and radio, it was easy for governments to control the dissemination of information to the population. With the Internet, information is no longer communicated through a few national official channels. However, governments which have traditionally controlled mass media have gradually also increased their control over search engines and strengthened censorship. One example is the Chinese authorities, who just recently decided to redesign their own search engine algorithms in Baidu to be more appropriate to the communist ideology. As one of the few countries in the world, they block Wikipedia too.

It is urgent that we to ask ourselves who should own our collective memory, which comprises the foundation of a healthy civic intelligence. Surveillance capitalism began when Google discovered that the data exhaust in online activities could be used to produce predictions of user behavior. This made it possible to control human knowledge in new ways and sell prediction products that are about individuals rather than for individuals. Knowing what you want to find before you know it yourself has been a long-term goal. The big tech companies' lack of respect for the privacy of the user has become a major concern (Zuboff, 2019).

We have yet to see the prosperous democratic culture that some hoped would emerge from Web 2.0. According to Mulgan (20 I 8: 2 I I), any kind of collective intelligence relies on a knowledge commons of some kind, even at the micro level. If we compare the stone tool teaching in Boxgrove 
500,000 years ago and the sharing of online videos today, it is evident that they both build on a human desire to share knowledge. Open access to knowledge is at the core of $\mathrm{CI}$ and constitutes the basis for informed political and scientific debates.

Nor is the surveillance society inevitable. A search engine like DuckDuckGo does not reveal any personal information. Today, there is more interest in developing new open source search engines and peer-topeer search engines. However, it is difficult to create a large-scale public index when Google dominates the market. There needs to be broad political support across countries in order to establish a "human knowledge project" (Halavais, 20I8). The recent emphasis on open access policies in scientific research also illustrates that the knowledge commons is gaining a more prominent position in democratic societies.

Furthermore, what is essential in civic intelligence is that human-tohuman intelligence is at the core of any system, although machine intelligence can still provide important support. Wikipedia has a number of bots that do simple work. In citizen science projects, computers have become better at doing image analysis, and they are now used in combination with human crowds (Sullivan et al., 20 I 8). Another example is how the Foldit community involves gamers in the further improvement of the game technology. A coding language called Lua can create a sequence of moves called recipes, which can perform one specific type of folding in the game. Thousands of player strategies are not only shared between gamers in the community, but they are also taught to the computers through machine learning. Some of the puzzle moves are then automated to make the game easier to play (S. Cooper et al., 2010: I2O-I22). This example illustrates the potential in a hybrid human-computer optimization framework that involves a community in designing the technology. The quality of the collective work can be improved by maximizing a large number of diverse contributions.

Furthermore, the many new democratic experiments across the world points towards the revival of a civic intelligence that was once at the core of the democracy in ancient Athens. Participatory democratic designs are being invented that involve both mass voting and mass deliberation in countries like Belgium, Ireland, Iceland, Italy, Mongolia, and Taiwan. They highlight that anyone both can and should participate in governing society. These experiments challenge the way we think about human capability, when all citizens are regarded as competent as competent, not just a small political elite. The many examples in this book show that $\mathrm{CI}$ is nourished by people who are different from each other, with different 
interests and unique perspectives. If these individuals show empathy towards each other and engage in critical discourse about their own society in a systematic manner, civic intelligence is likely to emerge. This will not only require participation in local communities, but also a sense of cosmopolitanism through global participation in the online setting.

Moreover, it is important to design local democracies in order to make people proud, encourage them to get involved, and become responsible citizens. This is not an issue about individual competence or technological superiority, but about how we can combine different types of collective problem solving in optimal ways. In contrast, instrumentarian intelligence assumes that algorithms can outperform human decision-making, enabling both a more efficient and accurate problem solving that is better and more fair compared with human collectives.

This tension between different types of intelligence is not new. Already in the middle of the twentieth century, Mumford criticized institutions in society because they did not fully serve human purposes. While civic life was diverse and multifaceted, institutions forced humans to participate in mechanical, power-focused hierarchies. Also at that time, Mumford feared that human life could end up being reduced to a mathematical order:

Of these vast transformations only an infinitesimal part is visible or can be reduced to any mathematical order. Form, color, odor, tactile sensations, emotions, appetites, feelings, images, dreams, words, symbolic abstractions that plenitude of life which even the humblest being in some degree exhibits cannot be resolved in any mathematical equation or converted into a geometric metaphor without eliminating a large part of the relevant experience. (Mumford, 1970: 54)

If we are to listen to Mumford, the plenitude of life cannot be solved through the algorithms of a reputation state without eliminating important aspects of human experience. Both man and nature are open systems that even the strongest machine intelligence can only capture a tiny part of. Echoing our time, he warns against reducing law, customs, and moral codes to quantifiable indicators (Mumford, I970: 191).

Still, this is exactly what instrumentarian intelligence and the reputation state does when it mathematizes human life. Both the surveillance capitalism and the Chinese social credit system (CSC) build on the belief that every aspect of human life can be calculated and managed. This is done by collecting enormous amounts of data from both the individual and the environment. It also brings forth increased use of surveillance cameras that aim to collect all types of micro behavior in the offline setting. 
Furthermore, the new ranking systems represent powerful disciplinary techniques that normalize a life based on a reputation score. With the help of surveillance technology, the CSC is designed to constantly examine human behavior, leaving no place for refuge or alternative behavior. As the system colonizes all informal spheres of people's lives, it becomes an even more powerful tool that can shape people's lives. Because the formal and informal spheres fuse together into one reputation score, a low score will have devastating consequences on all areas of an individual's life. The system both individualizes performances by turning people into low and high achievers, while at the same time it standardizes group behavior according to a few prioritized dimensions. As citizen strive to improve their score, their lives will inevitably become more uniform when narrowed to the behavioral indicators that matter most.

If we follow Mumford, he claimed that it was impossible to make human complexity calculable. Still, this is exactly what instrumentarian intelligence envisions. What if Mumford got it wrong? At the most fundamental level, this is perhaps a question about what we think a human being actually is. If we look back to our origins, how we first became human, we might find some clue to help us better understand what a "human-centered" intelligent society could look like.

Just recently, archeologists made astonishing findings of Homo sapiens fossils in Morocco, at Jebel Irhoud. Until now, the common story about how we became humans was that we suddenly evolved from more primitive humans in East Africa around 200,000 years ago. From then on, we first spread out to the rest of Africa, and then we went on to conquer the rest of the world. However, the new findings call for a rewriting of the textbooks. What is sensational is that the fossils date back 300,000 years ago. There was not one Adam and one Eve, nor "a cradle of humanity" at some specific location in Africa - there were many. "If there was a Garden of Eden, it was all of Africa," says Professor Jean-Jacques Hublin, one of the leaders of the excavation in Morocco (Callaway, 20I7; Ghosh, 20I7). There was no superior center, rather a dispersal of Sapiens species at multiple places in Africa. The features in the fossils from Morocco and other Sapiens-like fossils from elsewhere in Africa reveal the diverse origins of our species. There was a multitude of primitive human species, each of whom looked different, with their own unique strengths and weaknesses. Three hundred thousand years ago, the Sahara was green and connected with the rest of Africa. Animals that roamed the East African savanna would also come to Jebel Irhoud, and Sapiens would follow them. They moved out of their safe havens and engaged with unknown others, living at 
different locations. And these humans, just as other animals, changed their appearance gradually over hundreds of thousands of years. It was this constant evolving mix of human contact and networks that formed Sapiens (Callaway, 2017; Ghosh, 2017).

We now know that there was no single superior group, just a continent full of diverse groups that eventually mixed together. Modern humans grew from this combination of many different human species. Today, we are in many ways facing the same challenge, but with much more urgency, to bring together diverse humans from different countries in solving the great challenges of our time, like climate change or pandemics. A society built on civic intelligence will need to embrace the diversity of all human resources, which still lies at the core of collective intelligence, as it has throughout our history. This is a new creation narrative for the next millennia. 